\section{Summary of: \\ Is there scope for providing oral cancer health advice in dental access centres?}

\author{
M. Williams ${ }^{1}$ and S. Scott 2
}

\section{FULL PAPER DETAILS}

$1^{1 *}$ General Dental Practitioner and Specialist in Oral Surgery, Barn Court, Cropwell Road, Langar, Nottinghamshire, NG13 9HD; ${ }^{2}$ Lecturer in Health Psychology, Department of Oral Health Services Research \& Dental Public Health, Dental Institute, King's College London, Caldecot Road, Camberwell, London, SE5 9RT

${ }^{*}$ Correspondence to: Mr Mike Williams Email:mike.williamsmwdental@hotmail.co.uk

Online article number E16

Refereed Paper - accepted 27 May 2008

DOI: $10.1038 /$ sj.bdj.2008.875

${ }^{\circ}$ British Dental Journal 2008; 205: E16

\begin{abstract}
Objective There are more than 3,500 new cases of oral cancer each year in the UK. The purpose of this study was to establish the proportion of patients attending a dental access centre that are at risk of developing oral cancer because of lifestyle habits, and in turn determine whether access centres are a suitable location for the provision of advice on smoking cessation and alcohol consumption. Methods Data were collected prospectively about the smoking and drinking habits of patients attending a dental access centre in Nottingham. Three hundred and fifty-nine patients attended the dental access centre during the survey period. Patients were categorised into one of four groups ranging from low risk to high risk, according to their smoking history and alcohol intake. Results More than 50\% of patients attending the dental access centre were smokers, with almost $40 \%$ of the patients in high or very high tobacco and alcohol use groups. The majority of attendees were under 45 years of age. Conclusions Significant numbers of patients attending the dental access centre have lifestyle habits that make them vulnerable to oral cancer. Dental access centres could usefully provide opportunistic health messages to patients about risk factors in the development of oral cancer.
\end{abstract}

\section{EDITOR'S SUMMARY}

The authors' response to the question 'why did you undertake this research?' represents the purest and most exciting starting point for any investigation; curiosity based on observation. Working in a dental access centre, the authors had become aware of differences in the patient profile, compared with general practice. Extending that consciousness one stage further, revealed that the patients consumed higher levels of alcohol and tobacco making them potentially at greater risk from mouth cancer.

The next step in the chain of events was to see if the observation could be put to a practical use. In many ways it represents the appliance of science that typifies our professional approach to problem solving and patient care. Because the access centre patients are less likely to be regular attenders the next thought was to ponder whether their visits might therefore open up a relatively less common opportunity to provide some health education, specifically in the area of raising awareness of the causes of oral cancer.

That the reality is not as clear cut as logic might conveniently suggest is less important than the emergence of a potential new way of approaching this at risk population. By their nature, patients attending on a more casual basis have a different lifestyle and approach to health, risk taking and behaviour; a nature which may also make them less amenable to conventional oral and general health messages. This should not make us shrug and give up but, on the contrary, spur us to think of more creative ways of communicating.

Since the incidence of advanced versus early mouth cancer at diagnosis has improved little in recent years despite time and effort on education, health promotion and raising awareness, it may be that we do need to look at different ways of addressing the problem. Imaginative, proactive work based on initial curiousness such as formed the basis of this work is to be applauded and encouraged. What have you noticed in your professional life that has struck you as being out of the ordinary? Is there a research project there too?

The full paper can be accessed from the $B D J$ website (www.bdj.co.uk), under 'Research' in the table of contents for Volume 205 issue 8.

Stephen Hancocks, Editor-in-Chief 


\section{TO ACCESS THE BDJ WEBSITE TO READ THE FULL PAPER:}

- BDA members should go to www.bda.org

- Do not login on the BDA home page, if you are already logged in, please log out.

- Then, in www.bda.org click on the link to the BDJ in the top left of the screen. A new window will open. If a new window fails to open please check the settings of any pop up blocker software that you have installed on your computer.

- You will now be asked to login with your BDA website login details which are on your BDA membership card.

- Once your details have been entered you will be transferred to the BDJ website. If your login does not work please contact the BDA Membership Department on 02075634550.

- If you are not able to access the article on the BDJ website there may be an issue with your system's firewall. If so, return to the BDA homepage and click on the link 'BDJ access problems' and follow the step by step guide.

\section{COMMENT}

There has been a sustained drive to improve the results of cancer treatment in the UK. This drive has focused on early diagnosis as is illustrated by the introduction of two week wait clinics. These clinics are closely policed with breaches reported regularly to the cancer networks.

But diagnosing mouth cancer early in its development it not as simple as it sounds. My own data spanning the period 1961-2000 (Hull Royal Infirmary and Guy's Hospital) show that the incidence of advanced $v s$ early disease at diagnosis has remained static over the last 40 years (see table). This is despite efforts expended on education, public health promotion and general awareness of the cancer in the population.

So why has there been so little impact? The reasons are multifactorial. Only $40 \%$ of mouth cancers are diagnosed by dentists; the majority of patients consult their doctor. Also the patient is responsible for most of the delay (80\%) and to compound the problem the tumour is silent in about $1 / 3$ of cases. A Finnish study of 5,646 primary care visits showed how rare mouth carcinoma is and how common are the presenting symptoms. A physician would encounter an average of two new cases in a working lifetime but some $11 \%$ of all visits were made for symptoms which occur in patients with mouth cancer. Also the atrisk population do not attend the dentist or doctor regularly. The identification and targeting of this at-risk population has proved a problem.

In the present article Drs Williams and Scott have approach the issue from another direction. They show that in the population utilising dental access centres there is a relatively high proportion of individuals potentially at risk of mouth cancer. This opens up opportunities for health education and the introduction of alcohol and tobacco cessation strategies. The catch, however, is that the population is relatively young and the benefits of tobacco and alcohol cessation will only be felt 10 years or more in the future. The target has been identified but will the strategies work?

Professor M. McGurk, Department of Oral \&t Maxillofacial Surgery, Guy's Hospital
IN BRIEF

- Highlights the importance of the combination of alcohol and tobacco usage as risk factors for oral cancer.

- Encourages all dentists to ask appropriate questions about patients' smoking and drinking habits as part of a minimum data set during their examination process.

- Suggests dental access centres are potential locations for primary prevention of oral cancer.

\section{AUTHOR QUESTIONS AND ANSWERS}

1. Why did you undertake this research? The idea for the study followed a personal, clinical impression that a disproportionate number of patients attending the Integrated Dental Unit (IDU) in Nottingham reported high levels of consumption of tobacco and alcohol. The purpose of the study was then to confirm if this was the reality across the whole population accessing the IDU service, and not just those seen by an individual dentist.

With the broad assumption that by the very nature of the IDU service, these patients did not regularly attend for dental examination, it was recognised that they might usefully be targeted with health information to which they might otherwise never be exposed.

2. What would you like to do next in this area to follow on from this work?

On the face of it, there is no particular reason to believe that the population using the Integrated Dental Unit in Nottingham would be particularly different to that attending any other centre providing access to emergency dental care. However, this is not certain, and there would be merit in repeating this study in other similar units.

The next stage in the Nottingham Unit will be to carry out a study to determine the level of knowledge about risk factors for oral cancer held by high consumers of tobacco and alcohol. It will then be a matter of determining if, given the reality of patients attending in pain, the IDU could reasonably provide oral health information in a way that was appropriate and acceptable to patients, and in a format that could be retained by them. 